\title{
ABSOLUT SPOOF: SUBVERTENDO A PUBLICIDADE DA MARCA ABSOLUT
}

ABSOLUT SPOOF: SUBVERTING ABSOLUT'S ADVERTISING

Recebido em 03.09.2013. Aprovado em 14.05.2014

Avaliado pelo sistema double blind review

DOI: http://dx.doi.org/10.12712/rpca.v8i2.311

\author{
Renata Couto de Azevedo de Oliveira \\ renatacouto@yahoo.com \\ Pontifícia Universidade Católica do Rio de Janeiro - IAG/PUC-Rio

\section{Luís Alexandre Grubits de Paula Pessôa} \\ lpessoa@iag.puc-rio.br \\ Pontifícia Universidade Católica do Rio de Janeiro - IAG/PUC-Rio
}

\section{Resumo}

O objetivo do presente estudo é investigar como as paródias publicitárias (ou spoof ads) da marca Absolut Vodca veiculados no site da AdBusters Media Foundation, que possui destaque dentre os movimentos de resistência classificados como culture jamming, refletem as características e críticas apontadas na literatura sobre tal movimento. Trata-se de uma pesquisa exploratória com base em um estudo de caso dos spoof ads da marca Absolut. Os resultados apontam que muitas das características do movimento de culture jamming estão presentes no corpus analisado. Conclui-se, portanto, que os spoofs são elementos representativos do movimento jammer de resistência previamente mencionado.

Palavras-chave: Culture jamming. Resistência. Publicidade. Vodca Absolut. Spoofads.

\begin{abstract}
The aim of this study is to investigate how advertising parodies (or spoof ads) of Absolut Vodca brand found at the site of Adbusters Media Foundation, which features among resistance movements classified as culture jamming, reflect the characteristics and criticisms in the literature on such movement. This is an exploratory research based on a case study of Absoluts' spoof ads. The results show that many features of the culture jamming movement are present in the analyzed corpus. Therefore, it is concluded that those spoofs ads are representative elements of the resistance movement previously mentioned.
\end{abstract}

Keywords: Culture jamming. Resistance. Advertising,. Absolut Vodca. Spoof ads.

\section{Introdução}

A sociedade do consumo (BAUDRILLARD, 1995) é fortemente pautada em valores materialistas. Portanto, considera-se o consumo de bens e serviços como o ponto de partida de uma tarefa contínua de observação, pesquisa, análise e sistematização do comportamento do consumidor. Ao assumir um lugar central na vida cotidiana, o consumo, segundo Rocha (2005), estrutura os valores e práticas que regulam relações sociais, que constroem identidades e definem mapas culturais, regidas por um sistema de significados. Levy (1963) ilustra esse cenário quando afirma que somos aquilo que consumimos: as posses de um indivíduo são como extensões do 
seu "eu", exercendo um papel fundamental na definição de quem somos. Englis e Solomon (1997) corroboram tal ideia e a ampliam, argumentando que as preferências de consumo individuais representam uma informação importante tanto para o indivíduo em si quanto para os outros no processo de atribuir significado à identidade social.

Assim, podemos afirmar que existem fortes associações entre produtos e papéis e, portanto, uma determinada categoria de produtos e serviços é avaliada pela sua habilidade de transmitir mensagens socialmente relevantes dentro de uma determinada cultura, num determinado momento histórico (ENGLIS E SOLOMON, 1997). Tais significados são classificados pela literatura de marketing como sociais, em oposição aos significados utilitários (que envolvem atributos de performance) e aos hedônicos (relacionados a sentimentos, emoções e valores estéticos), como informa Suarez (2010).

Às vezes, apesar dos objetos estarem à disposição para consumo imediato, não conseguimos dar seguimento a tal tarefa, por um simples motivo: carecemos de significado, ou seja, de um sistema simbólico que complete os objetos, lhes atribuindo usos e razões, uma classificação capaz de oferecer sentido aos produtos ou, por fim, um sistema de mídia que recorte os produtos sob a forma de desejo, oferecendo significados sob a forma de utilidade (ROCHA, 2000).

Neste cenário, os universos da produção e consumo se apresentam como faces opostas de uma mesma moeda ou domínios opostos que serão conciliados pelos meios de comunicação contemporâneos (ROCHA, 2000; WALTHER, 2002). Na produção, segundo Walther (2002), o foco está nos produtos múltiplos e indiferenciados, na visão do homem como mera força motriz, excluindo-o de qualquer participação nos seus resultados. Tal entendimento remonta ao surgimento da industrialização e a correntes filosóficas e artísticas embasadas no "culto à máquina", como o Construtivismo russo e a Bauhaus alemã. Como fazer, portanto, que produtos indiferenciados se tornem aptos ao consumo por indivíduos cheios de peculiaridades e distinções? Como humanizar tais produtos e direcioná-los ao consumidor?

Com essas perguntas damos o primeiro passo no sentido de compreender melhor o papel da publicidade, da propaganda e também do sistema de marketing como responsáveis pela classificação da produção e socialização necessária ao consumo. Através deles a produção é traduzida, tornando o consumo exequível. A publicidade, como uma mágica, humaniza o produto e o direciona ao consumidor, promovendo uma aliança entre produtos, antes indiferenciados, e nomes, identidades, situações sociais, emoções e estilos de vida dentro dos anúncios (ROCHA, 1985).

Portanto, a publicidade, de acordo com Rocha (2000), torna público

(...) o significado atribuído ao mundo da produção, disponibilizando um enquadramento cultural e simbólico que o sustenta, (...) realizando a circulação de valores e socialização para o consumo. A cultura de massa libera o significado da produção dentro do universo do consumo e, neste sentido, reafirma que a cultura é pública porque o significado o é (grifo do autor), como nos ensina Geertz (1978). (ROCHA, 2000, p. 24)

Neste momento estabelecemos a ligação entre o sistema de produção; a publicidade, aqui entendida como chave decodificadora (ROCHA, 2000) deste sistema que viabiliza o consumo, classificando os compradores em categorias e levando em consideração a tendência humana de almejar pertencer a um grupo (WALTHER, 2002); e o movimento de resistência conhecido como culture jamming. 
De acordo com Walther (2002), baseado em Rocha (1985), a propaganda se compara ao mito em sua confecção e estrutura, pois é através dos mitos que uma sociedade exprime seus paradoxos, dúvidas e inquietações, constituindo um mundo mágico no qual os problemas são solucionados magicamente. Nesse mundo mágico, a propaganda transforma bebida alcoólica em amor, pasta de dente em sedução, convencendo o consumidor de que seus problemas reais podem ser solucionados pelo produto, suprimindo o cotidiano com vistas a criar uma nova realidade e, assim, aproximando-se também do conceito de rito, que consiste em um rearranjo de materiais que altera seus significados. 0 material presente no mundo real e cotidiano é recombinado através da propaganda ritualisticamente, sem perder sua essência, num exercício de "recontar a realidade" (WALTHER, 2002). Acreditamos que uma das bandeiras do movimento jammer - a luta contra a colonização dos espaços por tecnologias de marketing e mídia de massa - tenha como alvo a publicidade e o "rearranjo" por ela promovido, que suprime o que é real em prol do que é mágico, se abstendo de uma visão crítica do consumo de determinados produtos, em especial da bebida alcoólica, vez que o foco deste estudo é justamente o caso dos spoof ads da marca de vodca Absolut. 0 movimento jammer, dentro do contexto da resistência ao consumo, pode ser caracterizado, portanto, como uma reação à cultura de consumo e ao marketing de produção em massa de significados (PEÑALOZA E PRICE, 1993).

Neste contexto, o presente artigo apresenta o caso dos spoof ads (anúncios parodiados) da marca de vodca Absolut, veiculados pelo site da ONG canadense AdBusters Media Foundation, que possui destaque dentre os movimentos de resistência classificados como culture jamming. 0 objetivo do trabalho é apresentar, em uma perspectiva exploratória, como spoof ads, apenas uma das diversas manifestações do culture jamming, refletem características fundamentais desse movimento.

\section{Revisão de Literatura \\ Anticonsumo e Resistência ao Consumo}

Conceituar e diferenciar os termos anticonsumo e resistência ao consumo é tarefa complexa. Chauvel, Silva, Araújo e Hor-Meyll (2012) apontam que tais expressões têm sido usadas para designar oposição a práticas de empresas, a produtos/marcas, ou ao funcionamento do mercado.

Lee, Roux, Cherrier e Cova (2011) nos informam que existe uma diferença entre anticonsumo e resistência. 0 conceito de resistência, tal como delimitado pelo trabalho seminal de Peñaloza e Price (1993), engloba todas as respostas dos consumidores contra práticas de dominação dentro do mercado e que vão de encontro às suas crenças. 0 foco da resistência seria, portanto, uma assimetria de poder (FOUCAULT, 1975 apud em LEE ET AL., 2011), enquanto o do anticonsumo seria toda e qualquer preocupação relacionada ao consumo em si, e não com as relações de poder. Por outro lado, se entendermos consumo como o processo pelo qual as pessoas adquirem, usam e descartam bens comoditizados (entre eles serviços, marcas, produtos, ideias e experiências), anticonsumo seria, por extensão lógica e dentro do âmbito de estudos já existentes sobre o tema, todo e qualquer fenômeno que se caracteriza pela oposição à aquisição, uso e descarte de certos bens, não sendo sinônimo, contudo, para consumo alternativo ou consciente, tampouco englobando apenas questões éticas, sustentáveis ou envolvendo políticas públicas (FERNANDEZ E LEE, 2008). 


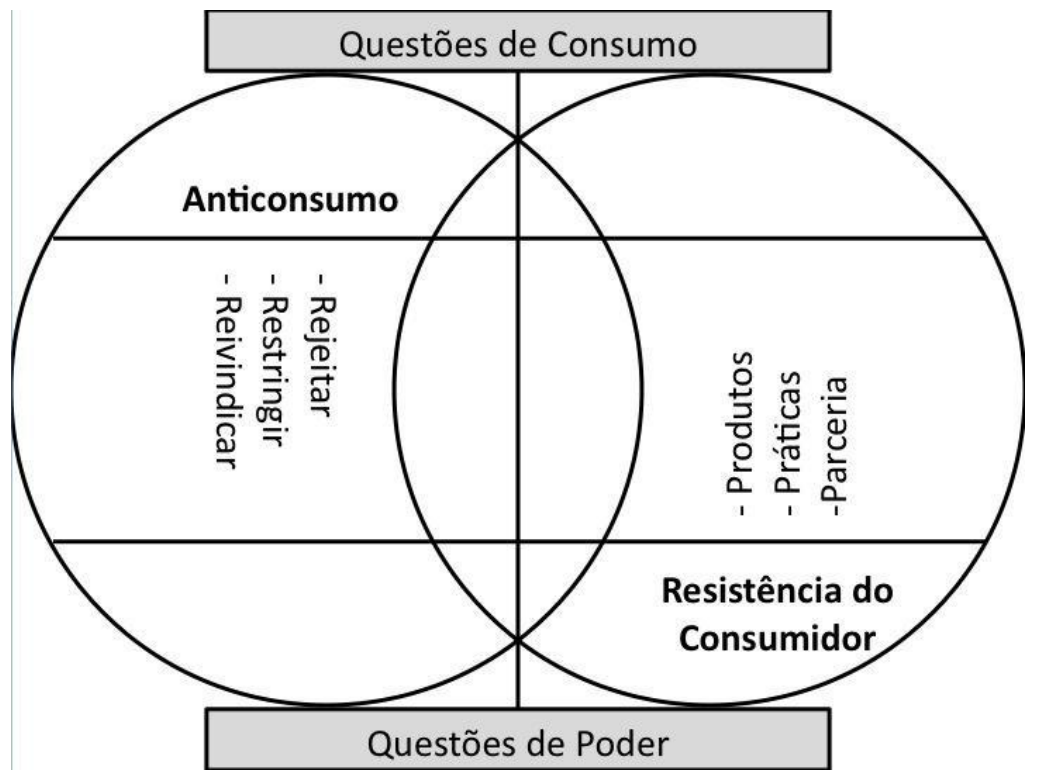

Figura 1 - Diagrama de Anticonsumo e Resistência do Consumidor Fonte: Adaptado de Lee et al. (2011)

O anticonsumo é classificado, por Lee et al. (2011), em três fenômenos não-excludentes rejeitar, restringir e reivindicar. Ao rejeitar bens, produtos e serviços, os indivíduos estão intencional e significativamente excluindo determinados bens do seu ciclo de consumo, enquanto, por sua vez, restringir implica na limitação, minimização ou corte do consumo quando o anticonsumo total não é viável. Por fim, reivindicar representa a busca de uma mudança ideológica a respeito do processo de consumo.

Em algumas ocasiões, entretanto, a resistência ao consumo é expressa através de atos de anticonsumo (LEE ET AL., 2011), direcionados contra grandes e autoritárias corporações, levando ao boicote de seus produtos, mas também é possível identificar casos de resistência através de atos de opções de consumo, quando, por exemplo, os consumidores optam por formar grupos que se afastam dos canais dominantes e tradicionais de varejo (KATES E BELK, 2001). Por fim, as definições de anticonsumo e resistência se diferenciam e, ao mesmo tempo, se sobrepõem, estando as práticas de anticonsumo mais voltadas para preocupações com o consumo, enquanto as de resistência se aproximam mais das preocupações com o poder.

Hogg, Banister e Stephenson (2008), por outro lado, entendem que a resistência ao consumo pode assumir a forma de comportamentos ativos, como boicote, consumo ético e simplicidade voluntária, enquanto a rejeição engloba produtos que não são comprados; serviços que não são acessados; e marcas que não são escolhidas, caracterizando comportamentos passivos e, portanto, mais difíceis de serem identificados e confrontados por gerentes de marketing. Todas esssas manifestações possuem, contudo, algo em comum, que é o objetivo de resistir à força ou ao efeito da cultura de consumo dentro do ambiente de mercado como um todo (CHERRIER, 2009).

Quando falamos sobre resistência, Cherrier (2009) indica que as práticas de anticonsumo estariam relacionadas ao desgosto ou, ainda, ao ressentimento em relação ao consumo em geral. Já a resistência ao consumo, de acordo com a mesma autora, não seria de fácil adoção, pois se recusar a adquirir determinados itens pode ser sentimental e financeiramente penoso, uma vez que, como ensina Belk (1998), é um fato inescapável da vida moderna que o indivíduo aprende sobre si próprio, se define e se lembra de quem é por meio das suas posses. 
É importante ressaltar, nesta etapa, a teoria de Ligas e Cotte (1999 apud SUAREZ, 2010), que versa sobre o desenvolvimento de significado da marca a partir da interação entre os ambientes de marketing, individual e social, dentro dos quais e através dos quais ocorre a transferência de significados (SUAREZ, 2010). Resumidamente, os ambientes podem ser explicados da seguinte maneira: 1) ambiente de marketing, em que ocorre a criação de significados de marca que podem resultar em brand equity para os produtos, ou seja, atalhos ou pistas para a memória que tornam as ofertas reconhecíveis e desejáveis. Contudo, Hogg et al (2008) sinalizam que tais mensagens enfrentam a concorrência de outras fontes de informação (como, por exemplo, empresas concorrentes e governo) e podem ostentar significados positivos ou negativos; 2) ambiente individual, no qual os consumidores exploram os significados criados pelo marketing e pela sociedade com o intuito de criar seus próprios significados para a marca; 3) por último, o ambiente social, no qual os significados individuais são negociados, transferidos e alterados através da interação no grupo.

Essa teoria é relevante para entendermos de maneira mais clara o conceito e os objetivos do movimento denominado culture jamming, haja vista que no âmbito de tal movimento de resistência ao consumo, os códigos culturais e de consumo gerados pelas marcas no ambiente de marketing e traduzidos por suas campanhas publicitárias são encarados negativamente pelos jammers, entendidos como símbolos da hegemonia das marcas em espaços na sociedade do consumo, completamente tomados pela mídia (DINIZ, 2010). Posteriormente, tais significados são alterados e transferidos por meio dos anúncios parodiados (spoof ads) produzidos e veiculados pelos jammers, com o intuito de auxiliar os demais consumidores a decifrar os códigos impostos pela sociedade do consumo.

\section{Culture Jamming}

A resistência ao consumo é reação de indivíduos e grupos contra a cultura de consumo e o marketing de produção em massa de significados (encarados como estruturas de dominação, segundo Peñaloza e Price, 1993), uma oposição ao sistema dominante fora do controle do consumidor, à própria cultura de consumo que sustenta a economia capitalista, marcada pelo materialismo (CHERRIER, 2008). Por outro lado, não se caracteriza como processo de superação de um poder dominante, mas como um processo interno de cada indivíduo, fruto de autoreflexão e auto-expressão, como ensina Cherrier (2009). Assim, apresenta-se um paradoxo: o consumidor depende do mercado, porém nutre antipatia por ele ou até mesmo deseja se emancipar de sua ingerência.

Peñaloza e Price (1993) destacam que a resistência se expressa de diversas formas, entre elas ações diretamente voltadas para a modificação do marketing mix (lutar contra a publicidade tradicional, por exemplo) e aquelas diretamente comprometidas com a modificação dos sentidos de uso (por exemplo, usar produtos de formas alternativas, diferentes daquelas para as quais foram desenvolvidos). Acreditamos que é nesta seara que se insere o movimento denominado culture jamming, conjunto de técnicas de intervenção e sabotagem, que podem estar inseridas nos movimentos anti-globalização e anti-consumo iniciados nos anos 90 (DINIZ, 2010), e que alteram e subvertem os símbolos comerciais impostos pelo marketing das grandes empresas por meio da publicidade, virando estes códigos contra os seus criadores (VIEIRA, 2007).

Este movimento de reivindicação dos espaços físicos e culturais engloba diversos grupos e formas de manifestação. Contudo, não existem motivações religiosas ou de classe, bem como não há uma organização política, apenas a ideologia de que "a livre expressão não tem sentido se a cacofonia comercial aumentou ao ponto de ninguém mais lhe ouvir" (DINIZ, 2010, p.2). Em seu livro "Culture Jam: The Uncooling of America" (1999, apud RUMB0, 2002), Kalle Lasn, editor do 
AdBusters, aponta o jamming como uma guerra de memes ${ }^{1}$ informativa a ser travada nos terrenos cultural e mental.

Diniz (2010) informa que os ataques dos jammers focam nos resultados das deformidades do sistema capitalista e implicações do processo de globalização, posicionamento apoiado por Rumbo (2002), que agrupa em dois temas principais as manifestações do grupo AdBusters: a colonização dos espaços por tecnologias de marketing e mídia de massa, oferecendo críticas à publicidade, comoditização, limitação da diversidade de informação por monopólios de mídia de massa e controle corporativo sobre o espaço público; e a degradação dos ambientes naturais resultante da globalização do crescimento econômico e do consumo, através de criticas à política econômica neoliberal global, avanços tecnológicos e consumo.

O culture jamming também se caracteriza pela adoção do aparato tecnológico como ferramenta, bem como das técnicas empregadas pelo discurso publicitário (DINIZ, 2010), com o intuito de subverter, pelo uso da ironia e da criatividade, ou, segundo Odou e Pechperyou (2010), do cinismo com viés subversivo, os códigos culturais e de consumo, frutos do que acreditam ser uma cultura midiatizada.

Sobre as origens e inspirações do movimento jammer, são vários os autores (DERRY, 1993; KLEIN, 2002; CAMMAERTS, 2007) que apontam a banda norte-americana de música experimental Negativeland e sua gravação denominada JamCon84, lançada em 1985 e reeditada em CD em 1994, como a responsável pela criação e introdução do termo no discurso popular. A ideia por trás da expressão culture jamming é a mesma de radio jamming, qual seja, que frequências públicas podem ser pirateadas e subvertidas com o intuito de promover uma comunicação independente, ou visando interromper frequências dominantes. Segundo Kalle Lasn (1999), fundador da AdBusters Media Foundation e editor da revista AdBusters, o movimento culture jamming é uma metáfora para a interrupção do fluxo de uma cultura de consumo saturada pela mídia.

Outra forte influência que determina de forma marcante a atuação jammer é o movimento situacionista (DERY, 1993; RUMBO, 2000, 2002; HAROLD, 2004; ASSIS, 2004; CAMMAERTS, 2007; SANDLIN E MILAN, 2008; DINIZ, 2010; ODOU E PECHPERYOU, 2010), tendo como figura de maior destaque Guy Debord. Muitos jammers se vêem como herdeiros diretos do movimento situacionista, que é tido como percursor dos críticos da cultura de consumo e fonte primeira de inspirações teóricas e práticas para o grupo AdBusters Media Foundation (RUMBO, 2002). A principal inspiração para os jammers vem do conceito de détournement, ou seja, pequenos atos de distúrbio utilizando elementos do Espetáculo ${ }^{2}$ de forma a promover a reflexão sobre os próprios (ASSIS, 2004) e recuperar a autenticidade da vida. Tais atos consistiam em reescrever conversas de personagens de histórias em quadrinhos populares, reformular a sinalização em fachadas de lojas, fazer colagens subversivas com imagens comerciais e governamentais, entre outras táticas (HAROLD, 2004). Contudo, Harold (2004) ressalta que apesar de alguns jammers reconhecerem a influência situacionista, estes eram contra a paródia como uma estratégia retórica, uma vez que ela manteria, ao invés de abalar, a visão da audiência sobre a verdade, ou seja, a audiência permaneceria inserida no e submetida ao Espetáculo.

\section{Spoof Ads}

Para falarmos sobre spoof ads, é necessária uma breve introdução sobre a organização conhecida como AdBusters Media Foundation. Trata-se de uma instituição canadense sem fins lucrativos, criada em 1989, apoiada por leitores e que publica uma revista de mesmo nome, com uma tiragem de 120 mil exemplares. Além da publicação da revista, outras atividades ${ }^{3}$ são promovidas e suportadas através de doações. 0 foco, em geral, é sempre o mesmo: preocupação 
com a erosão dos ambientes físicos e culturais por forças comerciais. ${ }^{4} 0$ nome da organização e de sua publicação tem como inspiração a expressão adbusting (usado normalmente como sinônimo de antipublicidade ou contrapublicidade), que nomeia a expressão mais conhecida do movimento culture jamming, apesar de não ser a mais utilizada, segundo Torró (2012). A contrapublicidade se baseia em ataques aos suportes e mensagens publicitárias, principalmente aos localizados em espaços públicos, visando reclamar tais dimensões em prol de todos nós. Em última instância, o AdBusters se autodenomina como "uma revista ecológica, dedicada à análise

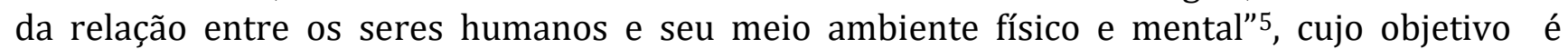
inspirar seus leitores a mover-se de espectador a participante.

"Anúncios são como notícias. 0 que há de errado com eles é que eles sempre são boas notícias" 6 , disse McLuhan (1994, apud HERLANDER, 2006). As paródias de peças publicitárias se enquadram no movimento denominado subvertising, que consiste, segundo Torró (2012, p.24), "na alteração das imagens, ícones e logos das marcas de uma forma irônica e cômica, refletindo o protesto contra as marcas e o consumismo." Sua origem data de 1972, quando posters da campanha política de reeleição do então presidente norte-americano Nixon foram modificados através da adição de outra letra " $x$ " ao nome do candidato, em referência à logo da marca Exxon, única patrocinadora da campanha política.

Subvertising é uma palavra que nasce da contração de duas outras: subvert (subverter) e advertising (propaganda, anúncio). As formas de subverter as peças publicitárias podem resultar em novas imagens, numa alteração de uma imagem que já existe ou na modificação/recontextualização de um slogan e, segundo indicação do próprio AdBusters, consiste em imitar a aparência e o sentimento do anúncio-alvo e promover em quem observa uma dissonância cognitiva (GATTI, CALLAWAY, STOCK E STRAPPARAVA, 2012).

Os spoof ads se caracterizam, por fim, como uma estratégia de defesa que visa alertar os consumidores de sutis pressuposições implícitas nas mensagens publicitárias e também reagir contra o excesso de publicidade, tão difícil de ser evitado (GATTI ET AL., 2012).

\section{Método}

0 presente trabalho pode ser caracterizado como uma pesquisa qualitativa exploratória que faz uso do estudo de caso (YIN, 2005) na etapa da pesquisa de campo.

O corpus foi coletado diretamente do site da AdBusters Media Foundation, acessado entre outubro de 2012 e junho de 2013. Constitui-se de um conjunto permanente de 7 (sete) spoof $a d s$, ou anúncios parodiados, da marca de vodca Absolut, que se mantiveram constantemente disponíveis na seção do site denominada "spoof ads" ao longo desse período. Nesta seção encontram-se diversas categorias de anúncios parodiados, entre eles os da marca Absolut, sob a classificação de Absolut Craze ${ }^{7}$.

Vale observar que os spoof ads foram analisados pelo seu conjunto. Apesar da riqueza de cada peça que compõe o corpus - característica que poderia justificar, em outro projeto de pesquisa, uma análise pormenorizada das peças -, buscou-se, neste trabalho uma abordagem geral do discurso representado pelo corpus de pesquisa. De acordo com Bauer e Aarts (2012), a construção de um corpus garante a eficiência que se ganha na seleção de algum material para caracterizar o todo, tipificando atributos desconhecidos, em contraste com a amostragem estatística aleatória, que apenas descreve a distribuição de atributos já conhecidos no espaço social. Cabe ressaltar também que, segundo Barthes (1967 apud BAUER E AARTS, 2012), o corpus consiste em uma coleção finita de materiais, determinada de antemão pelo analista, com (inevitável) arbitrariedade, e com a qual ele irá trabalhar. Por fim, nos resta destacar que, 
segundo Zikmund (2006), a pesquisa exploratória não permite fornecer evidências conclusivas necessárias para a determinação de cursos de ação concretas, visando apenas, portanto, conhecer mais sobre o assunto em questão. 0 trabalho aqui proposto está, portanto restrito à análise de uma das categorias de spoof ads elencadas pela própria AdBusters Media Foundation.

\section{O Caso Absolut \\ A Campanha Original}

Iniciada em 1979, a campanha de propaganda em mídia impressa baseada na imagem da garrafa da vodca Absolut incluiu cerca de 1.500 diferentes execuções impressas e se estendeu por 25 anos, tornando-se um caso de sucesso de ação de propaganda criativa e com aderência (MULLMAN, 2007). A campanha foi concebida em um contexto no qual as marcas importadas de vodca eram praticamente inexistentes nos Estados Unidos. Com efeito, na época, as marcas Stolichnaya (russa), Finlandia (finlandesa) e Wiborowa (polonesa) representavam menos de 1\% do mercado total do produto naquele país. Analistas creditam à campanha publicitária grande parte do sucesso que a marca alcançou, chegando ao topo da indústria de vodca, posição que deixou apenas no início da década de 2000, quando o segmento de mercado já contava com muitas outras marcas com posicionamento premium (CRESCITELLI E SHIMP, 2012).

Fazendo uso do nome da marca (que sugere inequivocamente o melhor produto, em absoluto) e o design diferenciado de sua garrafa ${ }^{8}$, a TBWA - agência responsável pela criação da campanha - adotou uma estratégia baseada na simplicidade. Todas as peças exibiam uma foto de página inteira da garrafa, com um cabeçalho de duas palavras: o nome da marca, Absolut, usado como adjetivo para modificar a segunda palavra que descrevia a marca ou o consumidor (Sofisticação absoluta, por ex.) ou, então, associava a marca a lugares ou eventos (Absolut Venice, por ex).
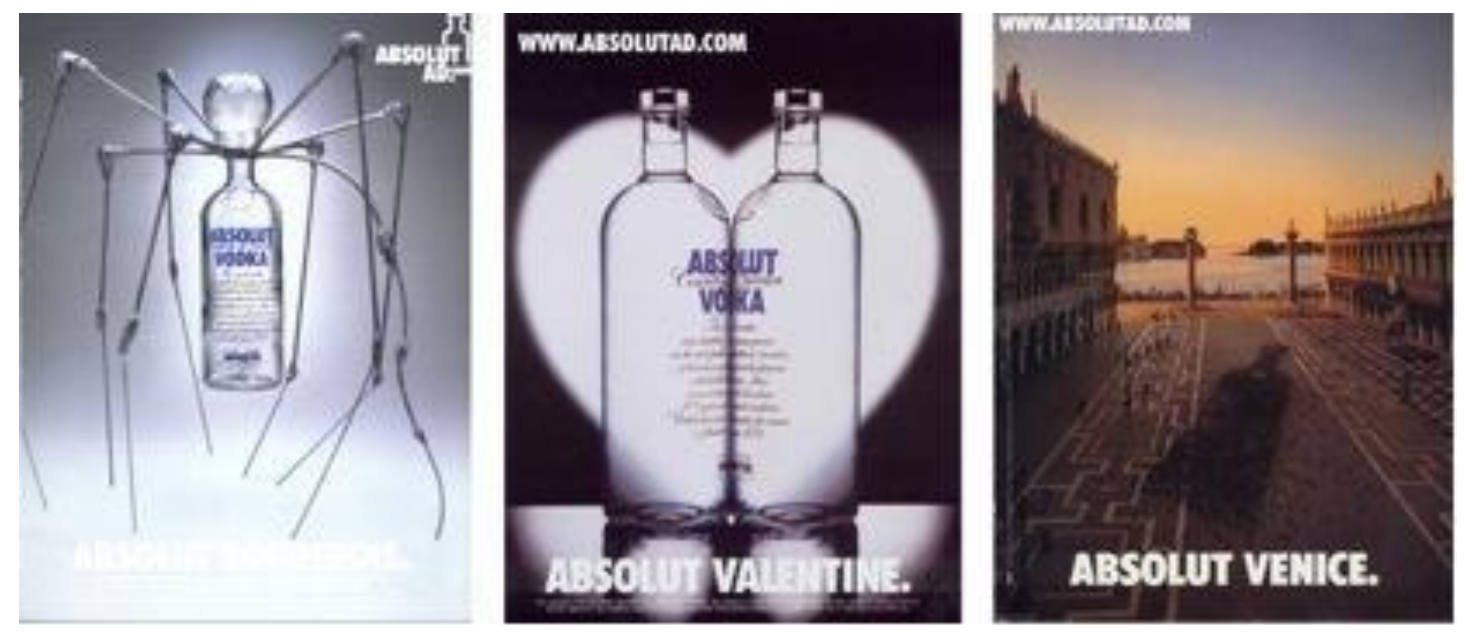

Figura 2: Exemplos de peças publicitárias oficiais da marca de vodcaAbsolut Fonte: Absolut Ad (http://www.absolutad.com/)

Nos Estados Unidos, a campanha foi retirada do ar em 2007, em função da percepção de esgotamento do tema e da necessidade de reposicionamento da marca. A nova campanha, "in an Absolut world" ("em um mundo Absoluto") continuava a jogar com o nome da marca, posicionando-a como a "vodca Absoluta", e apresentava imagens de como seria viver no "mundo Absoluto", ideal. Entretanto, a campanha tradicional da garrafa continuou a ser veiculada no Canadá, Europa, Ásia e América Latina (MULLMAN, 2007). 


\section{Absolut Spoofs: Os Spoof Ads da Absolut}

Inicialmente, deve-se mencionar que a escolha da organização canadense AdBusters se deve pelo fato da veiculação, em seu site, de spoof ads de diversas marcas internacionalmente conhecidas, entre elas a de vodca Absolut. Além disso, trata-se de uma organização que ganhou grande destaque dentro do movimento denominado culture jamming e também na mídia por suas campanhas como Buy Nothing Day ${ }^{9}$ Blackspot $^{10}$, bem como pelo movimento Occupy Wall Street.

No site da AdBusters Media Foundation, encontra-se uma seção inteiramente dedicada aos spoof ads. Dentre eles se destacam os que se apropriam da iconografia e da tipografia empregadas pela marca de vodca Absolut em suas campanhas oficiais, reunidos sob o titulo Absolut Craze ${ }^{11}$. No total são sete peças parodiadas, dentre eles quatro que se aproximam visualmente das campanhas originais da marca Absolut e três que se apropriam da silhueta da garrafa da marca de vodca e da palavra "Absolut", seguida por um substantivo.

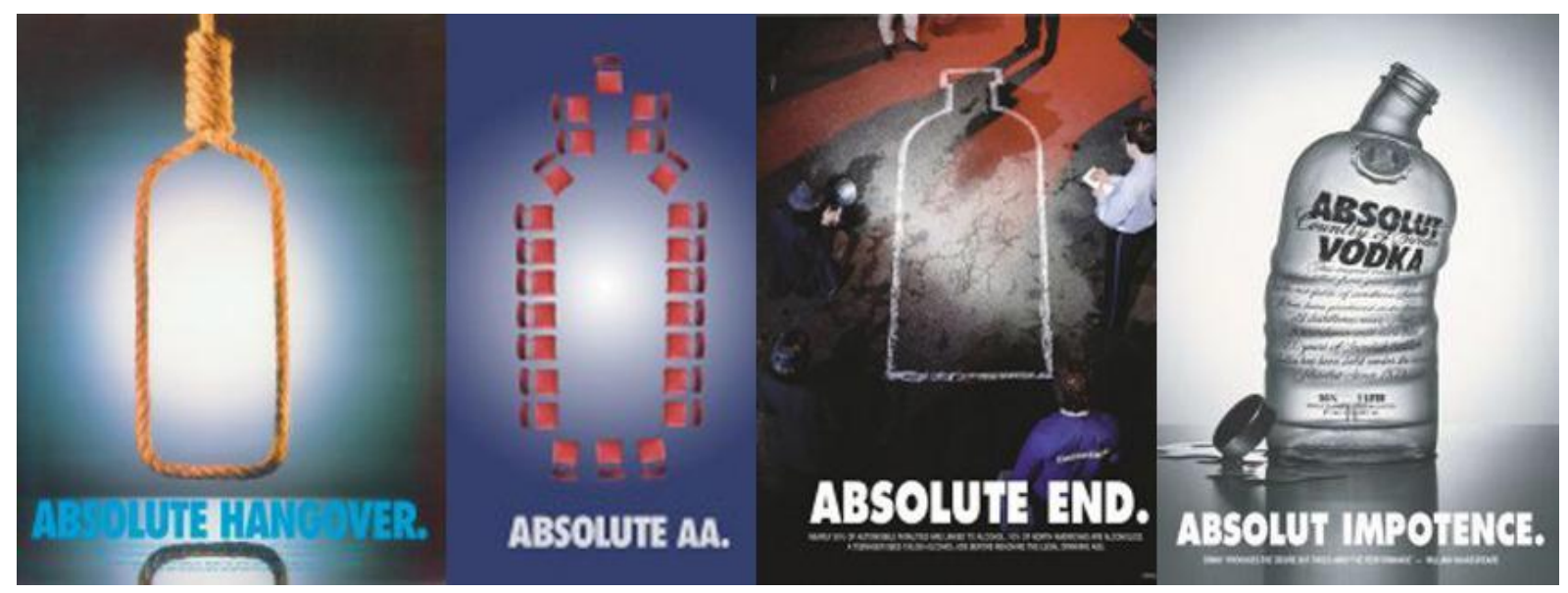

Figura 3: Spoof Ads inspirados nas campanhas da marca Absolut e que se aproximam delas.

Fonte: AdBusters Media Foundation (http://adbusters.org/spoofads/absolut-craze), acesso em 18/06/13.
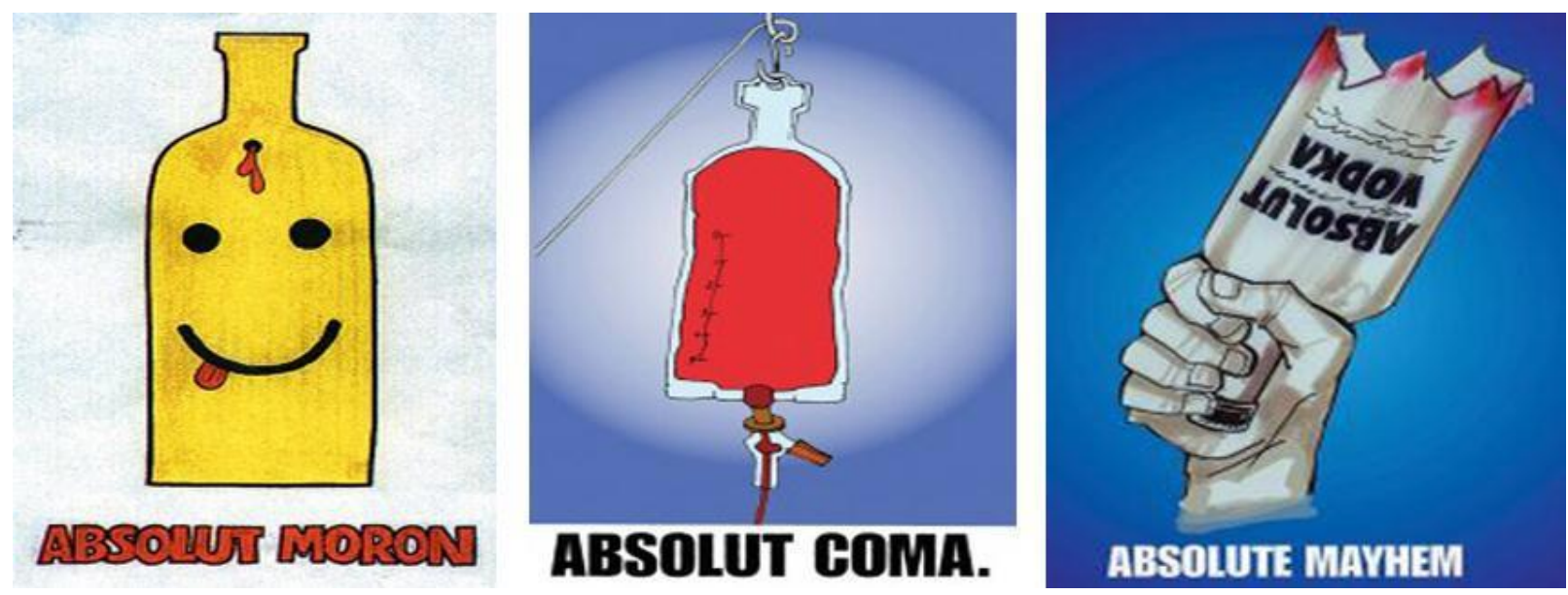

Figura 4: Spoof Ads inspirados nas campanhas da marca Absolut e que se apropriam da silhueta da garrafa, além da palavra "Absolut", seguida por um substantivo

Fonte: AdBusters Media Foundation (http://adbusters.org/spoofads/absolut-craze), acesso em $18 / 06 / 13$ 
Em comum, todos os spoof ads encontrados na categoria Absolut Craze possuem um tom irônico e, em geral, focam nos perigos e efeitos colaterais do consumo excessivo de álcool, contrastando com o universo criativo das peças publicitárias originais, nas quais as características do produto (o melhor produto, em absoluto) são transferidas e/ou associadas a datas (Dia dos Namorados, figura 2), lugares (Absolut Venice, figura 2) ou outras referências (no caso, referências artísticas, como na peça publicitária na figura 2 na qual a garrafa de Absolut aparece anexa à escultura "Maman", de Louise Bourgeois).

0 primeiro grupo, representado pela Figura 3, destaca as peças parodiadas que mais se aproximam visualmente das peças publicitárias originais, se apropriando de suas iconografia e tipografia. Aquelas poderiam, portanto, ser facilmente confundidas com essas se vistas rapidamente por um destinatário desatento. 0 foco dos spoofs em questão é uma crítica aos efeitos nocivos do consumo excessivo do álcool (ressaca, dependência, morte eimpotência).

Já o segundo grupo, representado pelos três spoofs da Figura 4, representa paródias que se valem da silhueta da garrafa de vodca Absolut, bem como da palavra absolut, seguida por um substantivo. Tais peças parodiadas não se parecem graficamente com as peças publicitárias oficiais da marca Absolut, porém são facilmente identificadas como uma critica à marca de vodca. As críticas aqui são também aos efeitos nocivos do consumo excessivo do álcool (como eu Absolut Coma, ou coma absoluto), porém os dois outros spoofs (Absolut Moron e Absolut Mayhem, ou seja, idiota absoluto e caos absoluto, respectivamente) não deixam muito claro quais seriam os alvos diretos de critica.

Em suma, verifica-se que muitas das características do movimento de culture jamming estão presentes no corpus analisado. Em primeiro lugar, trata-se de fato de um ato de détournement, no qual ocorre a alteração das imagens, ícones e logos das marcas de uma forma irônica e cômica, refletindo o protesto contras as marcas e o consumismo (TORRÓ, 2012). Com isso, esses spoofs visam imitar a aparência e o sentimento do anúncio-alvo e promover em quem observa uma dissonância cognitiva (GATTI ET AL., 2012), visando interromper o fluxo de uma cultura de consumo saturada pela mídia (LASN, 1999). Em segundo lugar, essa modificação ou recontextualização de um slogan, ícone ou logo é descrita por Maffesoli como uma tentativa de "compor com a sombra" ao invés de negá-la, ou seja, os jammers da AdBusters Media Foundation adotam não apenas o aparato tecnológico como ferramenta, bem como as técnicas empregadas pelo discurso publicitário (DINIZ, 2010), com o intuito de subverter os símbolos comerciais impostos pelo marketing das grandes empresas através da publicidade, virando estes códigos contra seus criadores, através da ironia e da criatividade. Em terceiro lugar, fica bem claro que esses jammers não possuem motivações religiosas ou de classe, nem mesmo uma organização política, tendo como foco de seus ataques tão-somente os resultados das deformidades do sistema capitalista e implicações do processo de globalização. Isso se manifesta não apenas nos spoofs, bem como em outras atividades da organização AdBusters, como, por exemplo, na campanha Blackspot e no discurso patrocinado pela própria organização sobre a venda de produtos que contribuem para financiar suas atividades ${ }^{12}$.

Apesar de representarem uma crítica à colonização dos espaços por tecnologias de marketing e mídia de massa, em especial à publicidade e seu potencial mágico para suprimir o cotidiano com vistas a criar uma nova realidade, promovendo um rearranjo de materiais que altera seus significados (ROCHA, 1985), os spoof ads empregados como estratégia subversiva pela AdBusters Media Foundation são alvos de algumas críticas, principalmente quanto à sua eficiência.

Uma possível crítica que poderia ser feita inicialmente ao movimento culture jamming e aos spoof ads é a que aponta a superficialidade dạs suas manifestações, voltando seus ataques não 
para as deformidades do sistema capitalista e implicações diversas do processo de globalização, como indica Diniz (2010), mas atacando somente o resultado na superfície, ou seja, as "expressões" desses processos através de um discurso marcado pela ironia e criatividade, contestando o que sentem no momento, ou seja, "o sufocamento pela falta de espaço para se expressar, já que na sociedade de consumo os espaços foram tomados pela mídia, e a mídia tomada por aqueles que possuem o capital para pagar por elas" (DINIZ, 2010, p.2). Trata-se, portanto, de um movimento e uma estratégia subversiva que exploram a experimentação e reapropriação simbólica e lingüística (DINIZ, 2010), compondo com a sombra, como sinaliza Maffesoli (2004 apud DINIZ, 2010), ao invés de negá-la.

Outra crítica, levantada por Odou e Pechperyou (2010), questiona a eficiência da estratégia pautada na subversão dos códigos culturais e de consumo, frutos do que se acredita ser uma cultura midiatizada, e sua exposição aos consumidores através da ironia, do cinismo e da criatividade. Embora o cinismo permita que o consumidor permaneça alerta, identifique rapidamente as tentativas de persuasão e resista a elas classificando-as como manipulação, Foucault (1986 apud CHERRIER, 2009) sugere que a resistência à dominação acaba sendo incorporada pelos produtores culturais, principalmente pelas marcas reflexivas irônicas (HOLT, 2002) que zombam da maneira tradicional de anunciar, como uma maneira de reforçar seu domínio. Assim sendo, cria-se uma afinidade com o consumidor e seu projeto de identidade cínico (MIKKONEN, MOISANDER e FIRAT, 2011). No entanto, Odou e Pechperyou (2010), relativizam a critica ao afirmar que, através do cinismo, uma poderosa ferramenta critica de enfrentamento, os consumidores conseguem recuperar o controle sobre sua existência, relevando a face oculta do marketing (CHERRIER E MURRAY, 2004 apud ODOU E PECHPERYOU, 2010), vendo a manipulação por trás da tentativa de persuasão e decifrando o código de consumo imposto pela sociedade de consumo. Assim sendo, o cinismo não se limitaria às técnicas de resistência ao marketing, mas poderia ser considerado como parte de um projeto global anti-consumista (KOZINETS E HANDELMAN, 2004; ROUX, 2007; LEE, MOTION e CONROY, 2009; CHERRIER, 2009; ODOU E PECHPERYOU, 2010).

Haiven (2007) aponta que tal movimento de resistência e, em especial o grupo AdBusters, é ineficaz como meio de luta contra a política do neoliberalismo e acaba tornando-se cúmplice dela. A tentativa da organização em questão de fazer com que os demais consumidores percebam a dominação à qual são submetido pelo uso da paródia apenas perpetua o compromisso com uma retórica dualista, comumente associada à ideologia de sistemas de opressão e dominação, sendo irônico que ativistas que buscam derrubar práticas sociais igualmente injustas e prejudiciais se sirvam dessa mesma narrativa em seus discursos (RUMBO, 2000; HAROLD, 2004; KOZINETS E HANDELMAN, 2004).

A paródia apenas favorece a manutenção da postura do ativista como "revelador da verdade" em comparação aos demais consumidores e tal tática possuiria resultados que são totalmente inadequados ao combate à cultura hegemônica do neoliberalismo, vez que essa estratégia apenas teria como resultado a substituição de uma ideologia dominante (das grandes corporações que dominam o espaço midiatizado) por outra (dos ativistas "iluminados", detentores da única verdade possível, sem brechas para ideias alternativas). Haiven (2007) também sugere que o jamming, principalmente o praticado pelo grupo AdBusters, não se identifica com as crenças situacionistas, conforme muitos autores e os próprios jammers acreditam, uma vez que os situacionistas visavam uma democracia mais verdadeira, bem como maior igualdade através de uma tentativa de fazer com que o público percebesse a opressão a qual era submetido, com o objetivo de fazê-lo rejeitar coletivamente o fascismo, o capitalismo e o socialismo estatal de baixo para cima. Em contraste, o jamming, em especial o praticado pelo grupo AdBusters, só concebe a existência de uma solução coletiva para os problemas do mundo 
se esta for precedida por um ato privado de libertação da mente, ou seja, a preocupação primeira é com a busca por autenticidade individual, e não com um projeto reflexivo ou universal de caráter coletivo, público. Contudo, segundo Haiven (2007), não pode haver consciência radical fora das tentativas coletivas de trazer justiça social (e vice-versa) e, portanto, as tentativas promovidas pelos jammers seriam ineficazes.

O mesmo autor também acusa o jamming praticado pelo AdBusters de simplificar e até mesmo ignorar dramaticamente modalidades e hierarquias de poder presentes da sociedade ocidental e que moldam (e são moldadas por) a cultura de consumo, como, por exemplo, raça e gênero. Assim sendo, a condenação ao consumismo sem considerar como ela é mediada, atenuada e definida dentro das estruturas sociais de poder não apenas torna o AdBusters incapaz de compreender a perpetuação e permutações do racismo e sexismo na sociedade contemporânea, bem como colabora tacitamente para a manutenção do dogma neoliberal de que o "campo de jogo" é igualmente nivelado para todos os grupos sociais. Em geral, poderíamos dizer que boa parte das criticas levantadas por Haiven (2007) estão diretamente ligadas ao fato da AdBusters Media Foundation se posicionar como uma organização na qual não existem motivações religiosas ou de classe, bem como não há uma organização política, apenas a ideologia de que "a livre expressão não tem sentido se a cacofonia comercial aumentou ao ponto de ninguém mais lhe ouvir" (DINIZ, 2010).

\section{Considerações Finais}

0 presente trabalho buscou estabelecer uma relação entre a sociedade do consumo (BAUDRILLARD, 1995) e os movimentos de anticonsumo e resistência ao consumo, com ênfase no exemplo do culture jamming e de uma de suas manifestações, qual seja, os spoof ads produzidos e veiculados pela organização canadense sem fins lucrativos conhecida como AdBusters Media Foundation. Os spoof ads, peças publicitárias parodiadas, são exemplos de subvertising, ou seja, subversão da publicidade, cujo objetivo é alterar e subverter os símbolos comerciais impostos pelo marketing das grandes empresas através da publicidade, virando estes códigos contra os seus criadores (VIEIRA, 2007). Esse recurso reflete as características do movimento de culture jamming capitaneado pela organização conhecida como AdBusters Media Foundation, conforme visto previamente.

Destacou-se, dentre os spoof ads disponibilizados no site da AdBusters Media Foundation, os que parodiam as peças publicitárias da marca de vodca Absolut, que se apropriam dos elementos gráficos da própria marca e dos utilizados nas campanhas oficiais. Concluiu-se que tais spoofs analisados são de fato representativos do movimento jammer em questão, refletindo tanto suas características, quanto as críticas feitas a tal manifestação.

Os spoof ads inspirados pelas peças publicitárias da marca Absolut se caracterizam como uma manifestação do movimento de culture jamming, que tem na organização conhecida por AdBusters Media Foundation um de seus expoentes. A tentativa de criar atos de détournement, nos quais ocorre a alteração das imagens, ícones e logos das marcas de uma forma irônica e cômica, refletindo o protesto contras as marcas e o consumismo (TORRÓ, 2012) fica evidente quando observamos tais spoofs. Também fica evidente que tais paródias, como aponta Haiven (2007), são superficiais e ineficazes, uma vez que condenam o consumismo, mas não se preocupam em situar tais críticas dentro do contexto das estruturas sociais. Parte desse problema aparenta ser consequência da postura de não filiação à entidades políticas, de classe ou religiosas adotada pela AdBusters Media Foundation.

Além disso, a tentativa dos jammers de promover o "despertar" dos consumidores através de tais atos de détournement por meio da paródia é encarada por muitos autores (RUMBO, 2000; 
HAROLD, 2004; KOZINETS E HANDELMAN, 2004) como uma mera perpetuação de uma retórica dualista, comumente associada à ideologia de sistemas de opressão e dominação, sendo irônico que ativistas que buscam derrubar práticas sociais igualmente injustas e prejudiciais se sirvam dessa mesma narrativa em seus discursos. A ausência de legendas e pequenos textos acompanhando os spoofs no site da AdBusters Media Foundation não colaboram para colocar os leitores da revista e/ou do site a par do contexto dentro do qual tais imagens foram produzidas, o que pode contribuir para o fracasso da empreitada de transmitir os valores e objetivos da organização jammer e, além disso, ser um indicador da perpetuação da retórica dualista.

Por fim, como aponta Holt (2002), a estratégia de adoção do tom reflexivo-irônico em publicidade como uma técnica pós-moderna voltou a ordem do dia na década de 1980 através das campanhas publicitárias de marcas como Levi's, Nike e Energizer, distanciando a marca dos conceitos tradicionais e excessivamente sensacionalistas e homogêneos da publicidade convencional, tornando-se ainda mais comuns ao longo da década de 1990. Tal mudança de estilo na publicidade contribuiu ainda mais para a incorporação da resistência pelos produtores culturais, principalmente pelas marcas reflexivas irônicas que zombam da maneira tradicional de anunciar, como uma maneira de reforçar seu domínio.

Por fim, deve-se registrar a hipótese de que as críticas ao movimento culture jamming poderiam ser atenuadas caso o presentes estudo contemplasse outras de suas manifestações que não apenas as paródias de anúncios, como grafites em fachadas de lojas e a realização de eventos. Nesse caso, poder-se-ia identificar outras formas de interação (LANDOWSKI, 2005) entre os participantes do movimento, as marcas e seus representantes e, finalmente, o público consumidor em geral. Analisar outras manifestações do movimento sob a ótica das interações entre sujeitos - sobretudo dos riscos e sentidos produzidos nessas interações - é, portanto, a principal sugestão de futuras pesquisas a partir do presente estudo. Outra possibilidade seria a realização de análises mais detalhadas de recursos do texto publicitário na criação de tais peças, explorando as demais categorias de spoof ads apresentadas no site da organização AdBusters Media Foundation.

\section{Notas}

${ }^{1}$ Meme é um termo criado por Richard Dawkins (1976), considerado como uma unidade de informação que se multiplica de cérebro em cérebro, ou entre locais onde a informação é armazenada (como livros) e outros locais de armazenamento ou cérebros. No que diz respeito à sua funcionalidade, o meme é considerado uma unidade de evolução cultural que pode de alguma forma autopropagar-se. Os memes podem ser ideias ou partes de ideias, línguas, sons, desenhos, capacidades, valores estéticos e morais, ou qualquer outra coisa que possa ser aprendida facilmente e transmitida enquanto unidade autônoma.

${ }^{2}$ A proposta do grupo francês situacionista parte da premissa de que a sociedade do século XX , denominada por Debord como "Sociedade do Espetáculo", alcançou o auge da passividade, da condescendência com o capitalismo como modo de vida e da falta de reflexão sobre o cotidiano, limitando-se a uma repetição mecânica e gozando de pequenas sessões de entretenimento vazio. Visando lutar contra o Espetáculo da vida cotidiana, que, segundo Boje (2001 apud SANDLIN E MILAN, 2008), consistia em tudo o que obscurecesse e legitimasse a produção violenta e o consumo, usurpando o livre arbítrio e a espontaneidade e substituindo-os com vidas patrocinadas pela mídia e experiências pré-embaladas (LASN, 1999), o grupo francês buscava gerar détournement.

${ }^{3}$ Para mais detalhes, conferir lista completa no site: http://www.adbusters.org/donate 
${ }^{4}$ Definição obtida no site AdBusters Media Foundation (http://www.adbusters.org), visitado em 7 de outubro de 2012.

5 Fonte: site AdBusters Media Foundation (http://www.adbusters.org), visitado em 7 de outubro de 2012.

${ }^{6}$ Livre tradução do original em inglês "Ads are 'news'. What is worng with them is that they are always 'good' news."

${ }^{7}$ Mania Absoluta ou Mania de Absolut (livre tradução).

80 nome do produto, segundo Liodice (2010), tem sua origem numa marca de vodca popular e o design da garrafa foi inspirado em frascos farmacêuticos do século XIX. Na época, tais decisões contrariaram o posicionamento de diretores de arte e executivos do setor de bebidas alcoólicas, além de pesquisas de mercado.

${ }^{9}$ Ativa desde 1992 e celebrada anualmente em mais de 65 países (SANDLIN E MILAN, 2008) nos dias 23 (na America do Norte) e 24 (ao redor do globo) de novembro, a campanha Buy Nothing Day consiste num "dia internacional de protesto contra o consumismo e é celebrado anualmente logo após o Dia de Ação de Graças, visando "instigar uma transformação pessoal", "uma emancipação radical", "uma epifania emancipatória" que possibilitará "sentir uma estranha magia rastejando de volta para a sua vida” (AdBusters, acessado em 02/05/13).

10Trata-se de uma "ambiciosa campanha antimarca" (HAROLD, 2004), lançada em 2003 e que consiste na produção de tênis em lona preta, com uma grande mancha branca no local onde se esperaria ver um logotipo corporativo aplicado. 0 objetivo da campanha, segundo Harold (2004), seria tornar a marca esportiva Nike uncool através da oferta de um produto produzido eticamente que fosse uma alternativa ao swoosh da marca. A campanha também incentivava os leitores da AdBusters a espalharem o "vírus Blackspot" grafitando manchas pretas nas lojas conceito da marca e em seus displays por todo Estados Unidos e Canadá. Contudo, tal campanha não foi bem vista por todos e muitos acusaram AdBusters de se vender ao mercado dos tênis. Lasn, que além de editor da revista AdBusters tornou-se também "CEO da Anticorporação Blackspot" (HAIVEN, 2007), declarou em entrevista que trata-se de uma "estratégia que pessoas irritadas têm para mudar o mundo para melhor", numa tentativa de "entrar no jogo sem se vender"

11 "Mania Absolut" (livre tradução).

${ }^{12}$ A própria Media Foundation reconhece que não é contra comprar e vender bens, pois trata-se de uma atividade inevitável. 0 que é rejeitado por tais ativistas jammers é, na verdade, o "capitalismo de consumo guiado pelas megacorporações". Como alternativa a tal "visão de mundo", a organização anuncia que seu "sonho" é um futuro menos focado no consumismo e mais voltado para um consumo de produtos produzidos por produtores locais e independentes. Por fim, é aunciado que todos os lucros resultantes das vendas são direcionados para a revista AdBusters e para as campanhas como Buy Nothing Day, Digital Detox Weel e Kick It Over. (AdBusters, acessado em 25/06/13).

\section{Referências}

ASSIS, E. G. O Novo Protesto: Táticas de Manifestação Midiatizadas em Movimentos Sociais. Trabalho apresentado no IV Encontro de Núcleo de Pesquisas da Intercom. Dispon vel em http://www.pontomidia.com.br/erico/rodape/ericoassis - taticas7 de manifestação 
midiatizadas.pdf (Acesso em 14/03/2013).

BAUDRILLARD, J A sociedade de consumo. Rio de aneiro Elfos Editora Lisboa Ediço es 70. 1995

BAUER, M.W.; AARTS, B. A Construção do Corpus: Um Princípio para a Coleta de Dados Qualitativos in Pesquisa Qualitativa com Texto, Imagem e Som: um manual prático, Martin W. Bauer, George Gaskell (orgs). 10.ed. Petrópolis, RJ: Vozes, 2012.

BELK, R.W. Possessions and the Extended Self. The Journal of Consumer Research, Vol. 15, No. 2, 139-168. 1998

CAMMAERTS, B. Jamming the political: beyond counter-hegemonic practices. Journal of Media and Cultural Studies, vol.21, no.1, 71-90.2007.

CHAUVEL, M.A.; SILVA, R.C.M. da; ARAÚJO, F.F. de; e HOR-MEYLL, L.F. Anticonsumo no Brasil: Reflexões sobre os Estudos Existentes e Proposta de uma Agenda de Pesquisa. VI Encontro Nacional de Estudos do Consumo: Rio de Janeiro, 2012.

CHERRIER, H. Anti-consumption discourses and consumer-resistant identities. Journal of Business Research, vol.62, no.2, 181-190.2009.

CRESCITELLI, Edson; SHIMP, Terence A. Comunicação de Marketing: integrando propaganda, promoção e outras formas de divulgação. São Paulo: Cengage Learning, 2012.

DAWKINS, R. 0 Gene Egoísta. São Paulo, SP: Companhia das Letras, 1976.

DERRY, M. Culture Jamming: Hacking, Slashing and Sniping in the Empire of Signs. Dispon vel em http //www.levity.com/markdery/culturjam.html (Acesso em 14/03/2013). Publicado originalmente em 1993.

DINIZ, J. R. Culture jamming - ativismo e contra-hegemonia. Revista de Estudos e Pesquisas em Linguagem e Mídia, Vol. 4 (1). 2010.

ENGLIS, B.G.; SOLOMON, M.R. Special Session Summary I am not Therefore, I am: The role of avoidance products in shaping consumer behavior. Advances in Consumer Research, Vol. 24, 61-63. 2007.

FERNANDEZ, K.V.; LEE, M.S.W. Anti-consumption: An overview and research agenda. Journal of Business Research. 2008.

GATTI, L.; Guerini, M.; CALLAWAY, C.; STOCK, O.; STRAPPARAVA, C. Creatively Subverting Messages in Posters. International Coference on Computational Creativity, Disponível em: http://computationalcreativity.net . Acesso em 07/10/2012.

GEERTZ, C. A interpretação das culturas. Rio de Janeiro, RJ: Zahar Editores, 1978.

HAROLD, C. Pranking Rhetoric "Culture amming” as Media Activism. Critical Studies in Media Communications, vol. 21, no.3, 189-211. 2004 
HAIVEN, M. Privatized Resistance: AdBusters and the Culture of Neoliberalism. The Review of Education, Pedagogy, and Cultural Studies, vol. 29, 85-110.2007

HERLANDER, E. A Sociedade Otimizada pela Mídia. Lisboa, Portugal: MediaXXI-FormalPress. 2006.

HOGG, M.K.; BANISTER, E.N.; STEPHENSON, C.A. Mapping symbolic (anti-) consumption. Journal of Business Research. 2008.

HOLT, D.B. Why Do Brands Cause Trouble? a Dialectical Theory of Consumer Culture and Branding. Journal of Consumer Research, volume 29, no. 1, 70-90.2002.

KATES, S.M.; BELK, R.W. The Meaning of Lesbian and Gay Pride Day. Journal of Contemporary Ethnography, vol.30, 392-429. 2001.

KLEIN, N. Sem Logo: A Tirania das Marcas em um Planeta Vendido. Sa o Paulo Record, 2002.

KOZINETS, R.V.; HANDELMAN, J. M. Adversaries of Consumption: Consumer Movements, Activism, and Ideology. Journal of Consumer Research, vol.31.2004

LANDOWSKI, E. Les interactions risquées. Limoges: PULIM, 2005.

LASN, K. Culture Jam: The Uncooling of America. New York: Eagle Brook.1999

LEE, M.; MOTION, J.; CONROY, D. Anti-consumption and brand avoidance. Journal of Business Research, vol.62, no. 2, 169-180. 2009.

LEE, M.; ROUX, D.; CHERRIER, H.; COVA, B. Anti-consumption and consumer resistance: concepts, concerns, conflicts and convergence. European Journal of Marketing, volume 45, issue $11 / 12.2011$

LEVY, S. J. Symbolism and Life Style. Toward Scientific Marketing, ed. Stephen A. Greyser, Chicago: American Marketing Association, pp. 140-150. 1963.

LIODICE, B. A Look Back at 10 Ideas that Changed the Marketing World. Advertising Age; $15 / 02 / 2010$.

MIKKONEN, I.; MOISANDER, J.; FIRAT, F. Cynical Identity Project as Consumer Resistance; the Scrooge as Social as a Social Critic. Consumption Markets and Culture, vol. 14, issue 1, 99-116. 2011.

MULLMAN, J. Why Absolut said bye-bye to the bottle. Advertising Age; 5/28/2007, Vol. 78, Issue 22, p.3-28.

ODOU, P.; PECHPEYROU, P. Consumer cynicism: From resistance to anti-consumption in a disenchanted world?. European Journal of Marketing, volume 45, no. 11/12, 1799-1808. 2010.

PEÑALOZA, L.; PRICE, L.L. Consumer resistance: A conceptual overview. Advances in Consumer Research, volume 20, 123-128.1993. 
ROCHA, E. Magia e Capitalismo: um estudo antropológico da publicidade. 3 ed. São Paulo: Brasiliense,1985.

Totem e consumo: um estudo antropológico de anúncios publicitários. Revista Alceu, Vol. 1, No. 1, pp. 18-37. 2000.

- Culpa e prazer: imagens do consumo na cultura de massa. Comunicação, Mídia e Consumo, Vol. 2, No. 3, pp. 123-138. 2005.

ROUX, D. Consumer resistance: proposal for an integrative framework. Recherche et Applications en Marketing, vol. 22, no.4. 2007

RUMBO, . D. The Case of AdBusters "Culture amming" as an Act of Resistance against the Acritical Discourse of Mass Advertising. Working Paper and Technical Report Series, no. 2000-06, University of Notre Dame, Department of Sociology. 2000

. Consumer resistance in a world of advertising clutter: The Case of Adbusters. Psychology \& Marketing, volume 19 (2), 127-148. 2002.

SANDlin, J. A.; MILAN, J. L. "Mixing Pop (Culture) and Politics" Cultural Resistance, Culture Jamming, and Anti-Consumption Activism as Critical Public Pedagogy. The Ontario Institute for Studies in Eeducation of the University of Toronto. 2008

SUAREZ, M.C. Criação, movimento e negociação de significados a partir do não consumo: um estudo do abandono das categorias de automóvel e cigarro. Tese de Doutorado, Pontifícia Universidade Católica do Rio de Janeiro, Rio de Janeiro, RJ, Brasil.2010.

TORRÓ, M. L. Nuevos paradigmas comunicacionales. La Publicidad de Guerrilla. Trabalho de final de curso, Universidade Abat Oliba CEU, Faculdade de Ciências Sociais, Barcelona, Espanha. 2012.

VIEIRA, T. de J. B. Artivismo - Estratégias artísticas contemporâneas de resistência cultural. Dissertação de mestrado, Universidade do Porto, Porto, Portugal. 2007.

WALTHER, L. C. da C. L. Imagem, Luxo e Dilema: Um Estudo sobre o Comportamento de Consumo das Patricinhas do Rio de Janeiro. Dissertação de Mestrado, Universidade Federal do Rio de Janeiro, COPPEAD, Rio de Janeiro, RJ, Brasil. 2002.

YIN, R.K. Estudo de caso: planejamento e métodos. 3. ed. Porto Alegre: Bookman, 2005.

ZIKMUND, W.G. Princípios de Pesquisa de Marketing. 2ed. São Paulo: Pioneira Thomson, 2006. 